Hussein Bougsiaa

Uniwersytet Gdański

\title{
Children within Mobile Technology: Interacting and Learning
}

Contemporary society is characterized by fragmentation, individualization and mobility in which cultural practices related to consumption, information and knowledge production (Elliott, Urry 2010), organization and distribution are "chunked", structured and connected in very different ways from lectures, webs and books (Traxler 2010: 110). Mobile technologies are increasingly embedded in the life-worlds of children. They allow children to deal with such fragmented and personally transformed knowledge and information. Because of the degree of integration with everyday life mobile technologies are considered as very important cultural resources which embody the social values and which are shaped by social structures, cultural practices and people's agency (Traxler 2010: 102). Mobile technologies are also important from an educational perspective as the convergent tools for meaning making, for engaging with and for mediating the world around students as well as communication with it. Their increasing portability, functional convergence and connectivity have a great potential for social interactivity, ubiquitous information retrieval, processing and exchange as well as context sensitivity and location awareness (Seipold, Pachler 2011: 2). Additionally, it has to be considered an increasing level of expertise of children in the use of mobile technologies and their participation in complex networking activities and communication.

Technology has become an essential element of our daily lives, affecting communication, education, relationships, the way we manage our finances, progress and develop. As we have become more immersed in the benefits and capabilities of these constantly developing technologies, children as well as adults have become avid users. Smartphones, tablets, iPods and other technologies developed specially for preteens. Software and game companies have been targeting children in their game development. Video games have become common entertainment for children as young as four years old. Children today can pick up a smartphone and quickly learn how to use all of its features, as if it were inherent to them.

Today children have a higher exposure to technology than any previous generation. Some believe that technology has provided a wide variety of benefits to 
children, and aided with their development. For example, technology allows for the classroom to be updated and education to be modernized to keep up with the ever-changing and high paced world. However, on the opposing side, some believe that technology is stunting children's development, and making them more prone to violence.

Contemporary children are described sometimes as the second generation of digital natives. They are individuals born around the end of the first decade of $21^{\text {st }}$ century. In contrast to the first generation of digital natives they have unprecedented access to technology. A substantial amount of homes in the western world have broadband which is provided via wifi. A personal computer (most often a laptop) and many others personal digital devices (smartphones, tablets etc.) can be found in most homes too. That means that the contemporary children users have access to high quality content on any device and that the location of the devices is not important since wifi provide the freedom and flexibility to consume digital content anywhere. A lot of contemporary digital devices come with the touchscreen. It means that the basic requirement to use such devices is a finger and even the youngest children mange to master the intuitive touch interfaces. Children do not even need to grasp the basic concepts of a language before operating a device. The fact that children can touch an interface and the interface is responding back to them is enough to stimulate them and encourage them to explore further.

Prensky's metaphor, the digital natives and digital immigrants, could be explained in terms of space and time: a place where access to technology is provided (technology is also equated to language in terms of immersion) and age as the defining factor used to assess the degrees of nativeness (Prensky 2012).

Digital natives are defined as those who are born into a world that just adopted computers and the web. They are called the native speakers of this technology. Many agree with Prensky that as a result of this exposure, digital natives do in fact think differently. They think in random access like hypertext, use instant information, construct knowledge in "audiovisual" ways because the way they think is directly influenced by the technology they use. With the notion of digital natives came the notion of digital immigrants. In Prensky's scenario, digital immigrants are those who although are not native speakers of the "technological language", they still have to live in the land of technology. They make use of traditional methods to develop and represent their thinking. They also need to at various stages represent their ideas via technological media. Digital immigrants share a lot of features with other immigrants who move to different countries where they confront different policies, cultures and above all other individuals who are natives in this environment (Prensky 2012).

The relationship of digital natives to technology is obviously different from past generations: technology is not just a tool but rather an important extension of their life. It is use to communicate, to learn, to entertain, to express oneself etc. They are not afraid to use it; as they are not afraid to expose themselves and their views on the online fora. On the other hand, just as in language, learning how to use technology does not mean that children can handle technology in different context and applications: just because child can use a device, it does not mean that he or she can apply this device to a more efficient context. 
Technology as a fact it does not transmute in any way, then enhanced transmutive pedagogy will associates with technology to create such a powerful possibilities, in education, technology particularly in this case means either effective or a way of technological tools involvement in an emancipator use in learning. As a notion, it concerns a numerous tools, of which media, devices, machines and networking hardware. Moreover; taking into the account the theoretical perspectives for their effective application. As we have to remember that technology is not restrictedly means Hi-tech. Nevertheless, the electronic environment including educational technology has become a vital part of our society's everyday life.

The contemporary educational technology widely includes as synonymous mobile learning, e-learning, instructional technology, information and communication technology in education, EdTech, learning technology, multimedia learning, technology-enhanced learning, computer-based instruction, computer managed instruction, computer-based training, computer-assisted instruction or computer-aided instruction, internet-based training, flexible learning, webbased training, online education, virtual education, personal learning environments, networked learning, virtual learning environments, which are also called learning platforms, m-learning, and digital education. Those tags have been differently utilized, conceptualized and conflate to a wide sphere of educational technology as well e-learning. Those substitutes descriptive terms are in whole a somewhat more restrictive than "educational technology" in here they are particularly and individually emphasize the digitization approach, component or delivery method. One of those modules m-learning, which emphasize the mobility, but are otherwise identically in fundaments from educational technology (Chen 2005: 91-100)

Within the educational technology there are various types of media that provides text, audio, images, animation and streaming video, and includes technology applications and processes such as audio or video tape, satellite TV, CD-ROM and computer-based learning, in addition intranet/extranet and web-based learning. Moreover, information and communication systems whether stand-alone or based on either local area networks or the internet networked learning, all determine many m-learning processes.

Mobile learning as the most powerful educational practices occur in or out of the classroom. It is manageable to be self-achieved; asynchronous learning or even instructor guided synchronous learning. It is full filling the distance learning as well in conjunction with in- person teaching, which is called differently "blended-learning". Educational technology is used by learners and educators in homes, schools or other settings freely.

\section{Important theoretical framework of mobile learning}

In the current m-learning discussion few theories are recognized as powerful conceptual framework: social-cultural ecology of m-learning and learner-generated context theory. 


\section{Socio-cultural Ecology of Mobile Learning}

The London Mobile Learning Group tries to provide a framework for the analysis of mobile learning which does not only highlight one specific aspects of mobile learning practices but also includes socio-economical and technological structures, agency of learners and their cultural practices (Pachler 2010: 153-167). By doing so, the learners life-world became a starting point for the appropriation of cultural resources such as mobile devices via agency and cultural practices within given or created structures. Appropriation is here understood as a process of producing and receiving engagement when students use mobile technologies. This process is described also as subjectively meaningful: students engage in meaning-making. Both, appropriation and meaning making is defined as situated, contextualized and subjectively shaped (Pachler 2010: 155). Learning - if understood as appropriation - is described as a process of meaning-making within the arrangements of social and technological structures, cultural practice and agency. For the mobile learning discussion the introduction of such model means a systematic extension of the domain of the learners' subjectively meaningful appropriation and meaning-making with the aim to position oneself in relation to everyday life or educational context (Pachler 2010: 156). Obviously, it offers prospects for education and formation.

\section{Learner Generated Context}

Alternative to the Social-Cultural Ecology concept is Learner Generated Contexts which is used to describe and understand the situational attitude of appropriation and the changes within the pattern of appropriation depending on place, time and availability of cultural resources (Brown 2010: 7-9). By referring to the context, formal and informal mobile learning situations and processes become describable, comprehensible and plannable for learning. Learner Generated Contexts concept gains importance because the context concept moves the focus away from user-generated contents and away from the idea of learning tools and preset learning contents. The increasing importance of agency of learners, technologies, structures, networks and contents creating within everyday life of students as well as within educational settings makes this concept powerful. This new concept also provides links to current developments in communication and to the contemporary understanding of learning as meaning-making in formal and non formal structures. Both move away from idea of learner being consumers of pregiven contents towards an idea of learners as producer of self-chosen and self-created contents: within contexts, students act in flexible ways and are able to adjust resources to the demands and conditions of contexts (Brown 2010: 42).

\section{Implementation of mobile learning in classroom-based learning practice}

Three common ways to implement mobile learning are identified in formalized educational settings. Often mobile devices are implemented into learning contexts from top to bottom: top-down approach (Seipold 2014: 42). It means that 
the devices are set-up onto already existing teaching and learning structures. Those are the cases of large budget projects in which whole departments or study programs are provided with mobile devices such as tablets. This approach implies strong regulation what means that students find themselves in pre-set and given technological infrastructure and scopes of action but this situation give them the equal opportunities within the learning process. This may be extremely important for the learners who are disadvantaged socio-economically and on an infrastructural level.

The alternative to the previous one is the bottom-up approach which consists on taking available resources, such as devices and know-how of students and teachers into account (Seipold 2014: 43). This approach obviously saves cost because devices do not need to be supplied and the students feel confident with their devices. Classroom seems to be open to the interests, competencies and knowledge based on the everyday life of students. However this approach can bring unexpected infrastructural challenges and obstacles for learning in terms of connectivity and technological transparency.

The third possible approach is demand-oriented one (Arnedillo-Sánchez 2008). This is an option closest to the everyday use of mobile technologies. The devices, applications and practices are used only when users teachers and students consider them necessary or helpful or when they are apply selectively and explicitly as teaching and learning tools. Such arrangements need to guarantee the seamless use of mobile technologies in class as well as outside it. Apart from this demand-oriented approach allows universities to be open to technology use in everyday life as appropriate and allows the design of lectures and workshop by keeping instructional, communicative and discursive learning, individual or in groups. Also it provides the wider selection among formal learning materials and resources or to refer to everyday life informal resources. Given the popularity, affordability, portability and flexibility of such devices, it is not surprising that educators have considered harnessing these devices within and beyond the classroom for educational purposes (Crippen, Brooks 2000; Liu 2007; Motiwalla 2007).

The integration of mobile technology at all levels of education is a current and ongoing topic of interest for children, parents, practitioners and researchers alike. As new technologies emerge or as new advancements become available for existing technologies, new opportunities for application to the educational environment become available. Most recently, emerging research is examining the impact of digital mobile technology for learning. The following section explores new research that examines how learners utilize hand-held mobile technology (e.g. iPods, iPads, iPhones and BlackBerry devices) for learning.

\section{Mobile technologies in the classroom and beyond}

In part, the desire to incorporate new technologies as part of instructional practice is a function of their ability to motivate children, encourage persistence on challenging tasks, and personalize the learning environment (Gee 2008; Hartnell-Young 2009; Looi et al. 2009; Specht 2010; Specht, Howell, Young 2007). In addition, the capabilities of these devices offer the potential for „anywhere, 
anytime", creative, and collaborative construction of knowledge (Evans, Johri 2008; Hoppe, Joiner, Milrad, Sharples 2003; Norris, Soloway 2008). The potential for learning with mobile technology has been equated with "21 $1^{\text {st }}$ century learning skills". Although multiple components constitute $21^{\text {st }}$ century learning skills, many frameworks identify creativity, collaboration, co-construction of knowledge, and an inquiry approach to learning (Dede 2010) as key or critical components. Mobile technologies also provide the opportunity for children to develop self-regulated learning skills (e.g. Pintrich 1995; Zimmerman 1989). Self-regulated learners know how to learn and are equipped with the cognitive skills and tools that allow them to learn. First, in the learning skills repertoire of self-regulated learners that make them effective learners, is their desire to learn that is, they are intrinsically motivated to learn. In addition, they acquire and possess high domain knowledge, as well as a variety of sophisticated strategies that allow them to learn effectively and efficiently. Finally, they engage in meta-cognitive behaviors that allow them to monitor their behavior and performance, set goals, and use effective strategies to maximize learning (Perry, VandeKamp, Mercer, Norby 2002; Willoughby, Wood, Khan 1994; Willoughby, Wood, Kraftcheck 2003). Together this constellation of cognitive skills prepares children to learn. When the model of the self-regulated learner is extended to include mobile technologies as a learning tool, the skill set also includes the ability to learn in collaborative contexts as well as being able to engage in construction of knowledge with access to the Internet at their fingertips. Self-regulation is a complex process that occurs over many years (Pressley, Hogan, Wharton-McDonald, Mistretta 1996). Although self-regulation takes time to achieve, educators can foster its development by designing the instructional content and choosing an instructional style to encourage learners to acquire the domain knowledge, strategies, and meta-cognitive skills needed to learn independently. At the same time, learning contexts must allow children the opportunity to learn from others and with others as well as from the myriad of information sources available to the learner through the Internet.

The potential of mobile technology for encouraging "self-regulated learning" and supporting constructivist pedagogy needs to be measured using learning outcomes that match the self-regulation theoretical framework. Constructivist pedagogy leading to "self-regulated learning" involves the following characteristics: it is student-centred; group dialogue leads to shared understanding; formal domain knowledge is introduced, both planned and unplanned; there are opportunities for children to challenge existing beliefs through engagement in structured tasks; and, there is development of meta-awareness of the student's own learning processes (Richardson 2003). Digital technology has enormous potential to be used as a cognitive tool to support all of these characteristics (Lajoie 2000). In order to assess whether mobile technologies have indeed supported self-regulated learning, gains in knowledge construction, learner motivation and satisfaction, and collaboration need to be evaluated along with student achievement levels (Lai et al. 2007; Wang 2003).

Along with the potential promise of mobile technologies as an educational tool, there are concerns regarding the practicality of introducing these devices in educational environments. For example, evaluation of mobile technology use has identified potential difficulties associated with the slow transmission of data, 
small screen and keyboard, and limited functionality in comparison to more traditional desktop and laptop systems. In addition, there are concerns that some of the functions that make mobile technologies so very attractive are the same functions that might inhibit or be detrimental for learning. For example, recent research found that children and young students reported learning decrements when they engaged in multi-tasking with Instant Messaging at the same time as trying to do school work activities (Junco, Cotton 2011). There are also concerns that over time, the functions that appear attractive to learners may become less attractive. For example, younger students demonstrated decreased persistence in engaged observation as part of the instructional task when asked to do photo-taking with PDAs (Lai et al. 2007). Overall, however, there is limited research examining how learners actually use mobile technologies.

\section{Defining mobile technology integration}

Before we discuss how to shift the role of the teacher in a classroom that is integrating technology, it is important to first define what mobile technology integration actually means. Seamless integration takes place when children are not only using technology daily, but have access to a variety of tools that match the task at hand and provide them the opportunity to build a deeper understanding of content. But how we define mobile technology integration can also depend on the kinds of mobile technology available, how much access one has to mobile technology, and who is using the mobile technology. For instance, in a classroom with only an interactive whiteboard and one computer, learning is likely to remain teacher-centric, and integration will revolve around teacher needs, not necessarily children needs. Still, there are ways to implement even an interactive whiteboard to make it a tool for your children. Willingness to embrace change is also a major requirement for successful mobile technology integration. Technology is continuously, and rapidly, evolving. It is an ongoing process and demands continual learning. „Effective integration of mobile technology is achieved when children are able to select technology tools to help them obtain information in a timely manner, analyze and synthesize the information, and present it. The mobile technology should become an integral part of how the classroom functions as accessible as all other classroom tools" (Hertz 2010).

When effectively integrated into the curriculum, mobile technology tools can extend learning in powerful ways. These tools can provide children and teachers with:

- Access to up-to-date, primary source material

- Methods of collecting/recording data

- Ways to collaborate with children, teachers, and experts around the world

- Opportunities for expressing understanding via multimedia

- Learning that is relevant and assessment that is authentic

- Training for publishing and presenting their new knowledge 


\section{Types of mobile technology integration use (where and how)}

It is sometimes difficult to describe how technology can impact learning because the term "mobile technology integration" is such a broad umbrella term that covers so many varied devices, tools and practices; there are many ways technology can become an integral part of the learning process. Just a few of these ways where mobile technology is possible to be used widely are listed below but new technology tools and ideas emerge daily:

- Learning with Mobile and Handheld Devices

- Project-Based Activities Incorporating Technology

- Game-Based Learning and Assessment

- Online Learning and Blended Classrooms

- Web-Based Projects, Explorations and Research

- Children-Created Media like Podcasts, Videos, or Slideshows

- Collaborative Online Tools

- Using Social Media to Engage Children.

\section{Levels of mobile technology integration}

Mary Beth Hertz shares four levels of classroom mobile technology integration, she has observed in schools:

1. Sparse: Technology is rarely used or available. Children rarely use technology to complete assignments or projects.

2. Basic: Technology is used or available occasionally/often in a lab rather than the classroom. Children are comfortable with one or two tools and sometimes use these tools to create projects that show understanding of content.

3. Comfortable: Technology is used in the classroom on a fairly regular basis. Children are comfortable with a variety of tools and often use these tools to create projects that show understanding of content.

4. Seamless: Children employ technology daily in the classroom using a variety of tools to complete assignments and create projects that show a deep understanding of content.

Despite the dramatic differences in resources and abilities from classroom to classroom, school to school, it's possible to integrate mobile technology tools in ways that can impact engagement and learning for all children.

\section{How is mobile technology used?}

A relatively recent study involved a comprehensive examination of the integration of digital mobile technology in the form of iPods, iPad and iPhone in elementary schools (Mueller, Wood, De Pasquale, Archer 2011: 415-416). Combining both quantitative and qualitative data provides a picture of use from both teacher and student perspectives. Specific children use, independent of prescribed teacher use, is considered in measuring the self-regulated learning supported by the mobile technology. Research was conducted at two elementary schools that used 
and accessed the mobile technology in different ways. At one school the devices stayed in the classroom and were only given to students at specific times for specific tasks. The school was well-equipped with technology with interactive white boards, document cameras and sound systems in each room, a set of computers in a common pod area for groups of three classrooms, as well as a fully functioning computer lab in the library. At the second school, each student received their own individual set of devices (iPod, iPad and iPhone) for the school year, which they had with them at school and at home and used as much or as little as they wanted. There was limited technology available in the rest of the school but a digital projector, document camera, and several computers were present and used in the participants' classroom.

At the first school seven classes (first grade class, one congregated enrichment class, one congregated special education junior class, and four junior classes ranging from grade four to six) were involved in the study. Before the formal study began, the students in the grade four class kept iJournals where they could write their thoughts and ideas about the mobile technology and what they expected to experience. At the beginning of the study, children filled out a survey assessing their attitudes, use, and knowledge of technology. The survey examined specifically their experience with mobile technology and how they used it outside of school. During the intervention with the mobile technology, class observations were conducted during lessons with and without the mobile technology on a weekly basis. Classes were videotaped and researchers kept a running record of the actions by the students in the classroom. Students also completed several online surveys on a semi-weekly basis, which asked about their devices use, enjoyment and whether or not the technology helped their learning or made it more difficult. At the conclusion of the study children were interviewed and asked about their views on the technology, specifically the mobile technology, and the impact it had on their learning. Focus group interviews with the students were conducted and recorded in groups of five to seven children at the end of the intervention period. During the interviews children were asked about their use of the mobile technology both at home and at school. They were also asked about the difference it made to their learning and whether or not they would recommend it to other students. The variety of learning contexts across the study (several different classes and grades in two different schools) resulted in three general levels of access for students: limited access within class; full-time access within class; and fulltime access within class and beyond. The three different contexts afforded students with unique learning opportunities and they utilized the mobile technology in different ways.

In general, children use of technology fell between "some” and „a lot" over the researches. Four general categories or types of use in the classroom were extracted from the qualitative research data (Mueller, Wood, De Pasquale, Archer 2011: 417).

1. Reference tool: children used functions of the device online editing and reference tools as well as specific Apps. The children who had full access to the mobile device more often indicated in the weekly surveys in their interviews and in most researches that the mobile technology was used as a reference tool and that all of their "tools" and work could be housed in "one place." 
2. Curriculum Resource: The mobile technology was also used off-line, that is, with specific applications that had been downloaded by their teacher and/or requested by children. The Apps provided information or an activity related to specific curriculum content, e.g. Planet Apps in science, musical instrument Apps in music, translation Apps in languages, drawing apps in Art, calculation games in Math, etc. Teachers in classrooms with limited access are often presented.

Activities that utilized the apps either individually or in pairs as either a component of a lesson (e.g. creating a Martian that they then described in a creative writing activity) or as the entire activity (e.g. writing vocabulary using Use Your Own Handwriting app). In some classes the set of devices were more often used as a whole class activity, whereas the primary class often used the devices with a small group in a centre rotation.

3. Research Tool: Both full access and limited access provided opportunities to use the mobile device as a research tool for "locating information", "answering questions", and "searching for pictures". Information was said to be "right there" without the need to travel to the library or start up a computer, providing the opportunity to answer questions immediately.

4. Strategic Learning Tool: children also showed the use of mobile technology for a multitude of purposes beyond curriculum and research. The technology was used to create and produce as well as to assess and assist in learning. Children used the devices to take pictures, record voice memos, listen to music, search for images, plan their day, generally help them learn, drawing, writing stories, typing, back-channeling, telling time, chatting, making a poster, and several other uses. The strategic use of the mobile technology as a learning tool was more apparent and available in classes that had ongoing, individual access either at school or at school and home. Some children even indicated that they had stopped using the iPod as much near the end of the year as they would soon be losing access.

\section{What were the children's attitudes and beliefs?}

The study of Mueller, Wood, De Pasquale, Archer indicated that children found using the iPods, iPads and iPhones to be enjoyable with mean scores all greater than three on a five point scale from zero (not at all) to four (a lot). In the same research, junior children included benefits of the iPods, iPads and iPhones to be speed and fun, e.g. "saves time", "not going to the library", "faster", ,quicker", „fun” (Mueller, Wood, De Pasquale, Archer 2011: 417).

Many interviewing data indicated that the technology made learning more engaging than books and teacher directed instruction. Some children indicated that the tool created social isolation in that "everyone is looking down at the little screen" and ,it is very quiet" when the iPods, iPads and iPhones were in use, while other children indicated that children were "excited to share what they were doing and what they found" on the iPods, iPads and iPhones. Children who were using the tool in a whole group are setting for specific activity shared information, links, and appropriate sites more often than individuals using the iPod 
as a strategic tool for a specific purpose other than searching. Classroom observations indicated that teachers included explicit opportunities for children to share to encourage collaboration but many children also did this spontaneously. When asked to explain how the technology supported their learning, children repeated their references to "ease" and "time" from the research. Children also indicated that the "just-in-time" feature of the mobile technology meant that they had the information at their finger tips and that it was searchable, in comparison to a book that has set content which could be outdated. Children who took the technology home were less enthusiastic about its potential outside the classroom, indicating for the most part, that they preferred a laptop if it was available. They did speak to the portability of the device and that they used it on bus transportation to listen to music and play games. Children in the special education class expressed their engagement with the mobile technology that in this case, was offered as one component in a suite of Web 2.0 collaborative tools and in-class computers (Mueller, Wood, De Pasquale, Archer 2011: 418).

\section{What were the barriers and support for children's learners?}

Children identified some issues and concerns with the technology, indicating that the small size posed some problems in viewing and typing but most qualified that by stating that it was overcome by the benefits of the device. The older, enrichment children who had full time access were not as positive, noting both benefits and drawbacks, analyzing when it was appropriate to use and when it was not. In that context, children also mentioned the "addictive potential" of the device and the responsibility of monitoring appropriate content and maintaining the technology (charging it, syncing it, not losing it, etc.) Classroom observations and interviews indicated that children were generally flexible in trouble shooting the devices, getting a different device if necessary, sharing with a partner, asking a friend to assist, and following short, visual and written instructions for entering Apps and search engines. When a problem occurred, it was not unusual for children to solve it individually or with other children before approaching the teacher. In fact, there were several instances where children demonstrated aspects and functions to the researchers/observers (Mueller, Wood, De Pasquale, Archer 2011: 420).

\section{What are the implications for learning?}

The variety of contexts and degree of access, as well as the variety of grades and learning needs, connected with the positive response across the majority of participants, suggests that mobile technology, such as the iPods, iPads and iPhones, are a versatile, engaging technology for children. It is flexible in its use and moves from a curriculum resource to a strategic learning tool as access increases. Differences between children who had full access and those with more limited access suggest that for the technology to be an integrated learning tool, it must be available and used on a regular basis. More limited access does allow for curriculum connections and easy, fast connections to searchable information. 
Although children were engaged with the technology, this was less apparent with some children who had full time access outside the classroom as well. It appears that these children did not see the need for the smaller device outside the classroom when a computer was available. It was, however, seen as a useful device in areas where a computer was not an option, for example, on the bus. For this group of children the mobile device was perceived as one of many learning tools available. The immediacy and ease of access to information and reference tools was perceived to be a strong benefit. Children demonstrated collaborative inquiry when using the mobile device to search for information and when troubleshooting around the device and its operation. The assistive features of the technology, e.g. voice memo or note taking Apps, served as scaffolds for children with learning challenges and supports for independent learning for all children. The flexibility of the device in terms of purpose and the variety of Apps available, suggest that it is capable of differentiating the learning process for children at different developmental stages, with different needs, and in different contexts.

Among the main benefits of using the mobile technology in classroom Mueller, Wood, De Pasquale, Archer (2011: 420) mention the following:

- Increases motivation

- Facilitates access to, management of, and sharing of information

- Fosters children learning and performance

- Allows a wider range of teaching strategies

- Fosters individualized learning

- Improves the reading experience

- Encourages communication and collaboration among children and between teachers and children

- Improves computer literacy skills

- Nurtures children' creativity

- A highly portable tool

- Facilitates student assessment

- Improves the quality of pedagogical support

- Facilitates learning how to write

- Makes it easier to organize schoolwork and assignments

- Children can make versatile and vivid multimedia presentations

- Significant benefits for children with learning problems.

As types of mobile technologies become increasingly available in schools and home contexts, children and teachers will need to explore and define the most optimal contexts for mobile learning tools. Obviously, most of the technologies mentioned above are nowadays in a very advanced stage and children and teachers can expect to master their use in the coming decade.

\section{Literature:}

Arnedillo-Sánchez I., 2008, The Mobile Digital Narrative Tool [in:] Mobile Learning, eds. I. Arnedillo-Sánchez, P. Isaías, Lisbon: IADISA.

Brown E., 2010, Introduction to location-based mobile learning [in:] Education in the Wild: Contextual and Location-Based Mobile Learning in Action, ed. E. Brown, Nottingham, UK: Learnin Sciences Research Institute, University of Nottingham. 
Chen J., Kinshuk J., 2005, Mobile Technology in Educational Services, "Journal of Educational Multimedia and Hypermedia" Vol. 14, No. 1.

Crippen K.J., Brooks D.W., 2000, Using Personal Digital Assistants in Clinical Supervision of Student Teachers, "Journal of Science Education and Technology" Vol. 9, No. 3.

Dede C., 2010, Comparing Frameworks for "21 ${ }^{\text {st }}$ Century Skills" [in:] 21st Century Skills: Rethinking How Children Learn. Bloomington, eds. J. Bellanca, R. Brandt, IN: Solution Tree Press.

Elliott A., Urry J., 2010, Mobile Lives, London-New York: Routledge.

Evans M.A., Johri A., 2008, Facilitating guided participation through mobile technologies: designing creative learning environments for self and others, "Journal of Computing in Higher Education" Vol. 20, Issue 2.

Gee J. P., 2008, Good Videogames, the Human Mind, and Good Learning [in:] T. Willoughby, E. Wood, Children's Learning in a Digital World, Oxford, UK: Blackwell Publishing.

Hartnell-Young E., 2009, The importance of teaching roles when introducing Personal Digital Assistants in a Year 6 classroom, „Technology, Pedagogy and Education” Vol. 18, Issue 1.

Hertz M.B., 2010, Integrating Technology with Limited Resources, http://www.edutopia.org/ blog/free-tech-integration-resources [access: 20.03.2013].

Hoppe H.U., Joiner R., Milrad M., Sharples M., 2003, Guest editorial: Wireless and Mobile Technologies in Education, "Journal of Computer Assisted Learning" Vol. 19, Issue 3.

Junco R., Cotton S., 2011, Perceived academic effects of instant messaging use, "Computers \& Education" Vol. 56, Issue 2.

Lai C.H. et al., 2007, Affordances of mobile technologies for experiential learning: The interplay of technology and pedagogical practices, "Journal of Computer Assisted Learning" Vol. 23, Issue 4.

Lajoie S.P., 2000, Computers As Cognitive Tools, Vol. 2: No More Walls, Mahwah, New Jersey: Lawrence Erlbaum Associates.

Liu T.C., 2007, Teaching in a wireless learning environment: A case study, „Educational Technology \& Society" No. 10.

Looi C.K. et al., 2009, Anatomy of a Mobilized Lesson: Learning "My Way", "Computers \& Education" Vol. 53, Issue 4.

Motiwalla L.F., 2007, Mobile Learning: A Framework and Evaluation, "Computers \& Education” Vol. 49, Issue 3.

Mueller J., Wood E., De Pasquale D., Archer K., 2011, Students learning with mobile technologies in and out of the classroom [in:] Education in a Technological World: Communicating Current and Emerging Research and Technological Efforts, ed. A. Méndez-Vilas, Badajoz: Formatex.

Norris C., Soloway E., 2008, Handhelds: Getting Mobile, http://www.districtadministration. com/ viewarticlepf.aspx?articleid $=1638$ [access: 29.09 .2009 ].

Pachler N., 2010, The Socio-Cultural Ecological Approach to Mobile Learning: An Overviews [in:] B. Bachmair, Medienbildung in neuen Kulturräumen: Die deutchsprachige und britische Diskussion, Wiesbaden: VS Verlang fur Sozialwissenschaften.

Perry N.E., VandeKamp K.O., Mercer L.K., Nordby, C.J., 2002, Investigating Teacher-Student Interactions That Foster Self-Regulated Learning, "Educational Psychologist" Vol. 37, Issue 1.

Pintrich P. (ed.), 1995, Current Issues in Research on Self-regulated Learning: A Discussion With Commentaries [Special issue], "Educational Psychologist” Vol. 30, Issue 4.

Prensky M., 2012, From Digital Natives to Digital Wisdom, London: Sage.

Pressley M., Hogan K., Wharton-McDonald R., Mistretta J., 1996, The Challenges of Instructional Scaffolding: The Challenges of Instruction That Supports Student Thinking, „Learning Disabilities Research and Practice. Special Issue: Contructivism and Children with Special Needs: Issues in the Classroom" Vol. 11, No. 3.

Richardson V., 2003, Constructivist Pedagogy, "Teachers College Record" Vol. 105, No. 9.

Seipold J., 2014, Mobile Learning. Structures, Concepts and Practices of the British and German Mobile Learning Discussion from a Media Education Perspective, „MedienPädagogik” Nr. 24. 
Seipold J., Pachler N., 2011, Evaluating Mobile Learning Practice, „MedienPädagogik” Nr. 19. Specht J.A., 2010, Strategies for Engaging Children with Learning Disabilities [in:] Classroom Communication, ed. C. Black, Madison, WI: Atwood Publishing.

Specht J.A., Howell G., Young G., 2007, Students with Special Education Needs and Their Use of Assistive Technology During Transition to Secondary School, "Childhood Education" Vol. 83, Issue 6.

Traxler J., 2010, Education and the Impact of Mobiles and Mobility: An Introduction to Mobiles in our Societies [in:] B. Bachmair, Medienbildung in neuen Kulturräumen: Die deutchsprachige und britische Diskussion, Wiesbaden: VS Verlang fur Sozialwissenschaften.

Wang Y.S., 2003, Assessment of learner satisfaction with asynchronous electronic learning systems, "Information \& Management" Vol. 41, Issue 1.

Willoughby T., Wood E., Khan M., 1994, Isolating Variables That Impact or Detract from the Effectiveness of Elaboration Strategies, "Journal of Educational Psychology" Vol. 86.

Willoughby T., Wood E., Kraftcheck E.R., 2003, When can a lack of structure facilitate strategic processing of information?, "British Journal of Educational Psychology” Vol. 73.

Zimmerman B.J., 1989, A Social Cognitive View of Self-regulated Academic Learning, "Journal of Educational Psychology" Vol. 81, No. 3.

\section{Summary}

\section{Children within Mobile Technology: Interacting and Learning}

Dzieci i mobilne technologie: interakcje i uczenie się

This article analyses the research question of how learners utilize hand-held mobile technology for learning of children. Mobile technology is an , anywhere, anytime”, creative learning tool that has the potential to support the development of self-regulated learners. The article examines user defined utilization of the mobile technology in elementary education settings: a comprehensive examination of the integration of digital mobile technology in an elementary school. Specific student use, independent of prescribed teacher use, is considered in examining the self-regulated learning supported by the mobile technology.

Keywords

children, mobile technology, mobile learning, school

\section{Słowa kluczowe}

dzieci, mobilne technologie, mobilne uczenie się, szkoła 